BUDGETING : Journal of Business, Management and Accounting

Volume 1, Nomor 2, Juni 2020

e-ISSN: $2715-2480$

p-ISSN: 2715-1913

DOI : https://doi.org/10.31539/budgeting.vli2.807

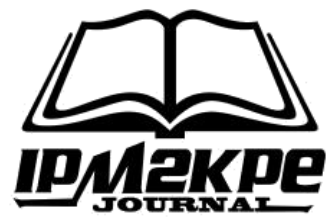

\title{
PENGARUH FREE CASH FLOW TERHADAP KEBIJAKAN HUTANG
}

\author{
Lulu Almarjan $^{1}$, Deni Muhammad Danial' ${ }^{2}$, Dicky Jhoansyah ${ }^{3}$ \\ Universitas Muhammadiyah Sukabumi ${ }^{1,2,3}$ \\ Lulualmarjan29@gmail.com ${ }^{1}$
}

\begin{abstract}
ABSTRAK
Penelitian ini bertujuan untuk mengetahui seberapa besar pengaruh arus kas bebas (Free Cash flow) terhadap kebijakan utang pada PT Indofood Sukses Makmur Tbk. Metode yang digunakan dalam penelitian ini adalah metode deskriptif dan asosiatif dengan pendekatan kuantitatif. Data yang digunakan adalah data laporan keuangan tahunan PT Indofood selama 8 tahun dari tahun 2011 sampai tahun 2018. Pengujian statistic yang digunakan adalah perhitungan, analisis menggunakan regresi linear sederhana termasuk uji koefisien determinasi. Hasil penelitian menunjukkan variabel arus kas bebas mendapatkan nilai signifikansi 0,008 yang berarti ada pengaruh arus kas bebas terhadap kebijakan hutang perusahaan PT Indofood Sukses Makmur Tbk. Simpulan, ada pengaruh yang signifikan dan hubungan yang kuat dengan arah positif variabel arus kas bebas (free cash flow) terhadap kebijakan utang pada PT Indofood Sukses Makmur Tbk.
\end{abstract}

Kata kunci : Free Cash Flow, Kebijakan Hutang

\section{ABSTRACT}

This study aims to determine how much influence the free cash flow on debt policy at PT Indofood Sukses Makmur Tbk. The method used in this research is descriptive and associative methods with quantitative approaches. The data used is PT Indofood's annual financial statement data for 8 years from 2011 to 2018. The statistical test used is calculation, analysis using simple linear regression including the coefficient of determination test. The results showed that the free cash flow variable gained a significance value of 0.008, which means that there was an influence of free cash flow on the corporate debt policy of PT Indofood Sukses Makmur Tbk. Conclusion, there is a significant influence and strong relationship with the positive direction of the variable free cash flow (free cash flow) on the debt policy at PT Indofood Sukses Makmur Tbk.

Keywords: Free Cash Flow, Debt Policy

\section{PENDAHULUAN}

Pembiayaan merupakan elemen terpenting dalam sebuah perusahaan, karena dengan adanya dana yang dimiliki, maka perusahaan akan mencapai tujuannya, yaitu akan menghasilkan keuntungan. perusahaan selalu memiliki hutang karena hutang merupakan kewajiban yang dimiliki oleh suatu perusahaan yang bersumber dari dana eksternal, baik yang berasal dari pinjaman perbankan maupun pinjaman obligasi dan 
atau sejenis lainnya, maka dari itu perusaahan yang besar akan memiliki kewajiban atau hutang yang besar pula (Buchory \& Saladin, 2010).

Kebijakan hutang merupakan bagian dari perimbangan jumlah hutang jangka pendek, hutang jangka panjang dan kebijakan yang diambil oleh pihak manajemen dalam rangka memperoleh sumber pembiayaan bagi perusahaan sehingga dapat digunakan untuk pembiayaan aktivitas operasional perusahaan.

Laporan pembiayaan aktivitas operasional perusahaan sangat penting untuk menggunakan Laporan arus kas, merupakan laporan yang melaporkan keluar masuknya arus kas didalam perusahaan selama satu periode. Laporan arus kas sangat berguna bagi perusahaan karena memberikan informasi mengenai kemampuan suatu perusahaan dalam menghasilkan kas dari aktivitas operasi, melakukan investasi, melunasi kewajiban, dan membayar deviden. Dalam suatu perusahaan, free cash flow atau arus kas bebas berperan penting karena jika free cash flow nya besar maka berpengaruh terhadap perusahaan untuk menunjukan bahwa perusahaan mampu mengembalikan tingkat pengembalian modal (Dharmmesta, Basu Swastha dan Handoko, 2014).

Salah satu indikator penting dari posisi arus kas perusahaan adalah arus kas bebas (free cash flow) yang dimiliki perusahaan. Posisi kas yang dimiliki perusahaan merupakan faktor penting dalam melakukan sehat atau tidaknya suatu perusahaan. Hal ini dikarenakan kas merupakan darah perusahaan yang dapat digunakan untuk membiayai seluruh aktivitas perusahaan (Werner R murhadi, 2013).

Tema yang diusulkan oleh peneliti dalam penelitian ini yaitu analisis pengaruh free cash flow terhadap kebijakan hutang. Tujuan penelitian ini yaitu untuk mengukur dan menganalisis pengaruh free cash flow terhadap kebijakan hutang PT Indofood Sukses Makmur Tbk.

\section{KAJIAN TEORI}

\section{Free Cash Flow (FCF)}

Laporan keuangan yang diterbitkan di go public setiap tahun dan setiap periode secara garis besar, laporan keuangan yang telah diproses sebelumnya oleh auditing lalu di publikasikan pada setiap ahir tahun nya maka laporan keuangan akan diterbitkan, PT Indofood Sukses Makmur Tbk memberikan informasi tentang free cash flow terhadap 
kebijakan hutang pada PT Indofood Sukses Makmur Tbk. Adapun rumus free cash flow yaitu :

Free Cash Flow $=$ Arus Kas Oprasi - Belanja Modal

$$
\text { Gitman (2009:131) }
$$

Nilai emosional merupakan perasaan atau tanggapan konsumen pada saat ingin melakukan keputusan pembelian pada dasarnya hanya merupakan sedikit perhatian untuk mencapai nilai kepuasan diri dari penggunaan produk/jasa" (Erik Sudarso 2016), (Aisyah 2004). Nilai emosional berhubungan dengan perasaan, yaitu perasaan positif yang akan dialami oleh pelanggan pada saat membeli produk (Surachman 2008).

\section{Kebijakan Hutang}

Kebijakan hutang merupakan kebijakan yang diambil oleh pihak manajemen dalam rangka memperoleh sumber pembiayaan bagi perusahaan sehingga dapat digunakan untuk membiayai aktivitas oprasional perusahaan. Kebijakan hutang juga berfungsi sebagai alat untuk monitoring terhadap tindakan menejer yang dilakukan dalam pengelolaan perusahaan karena kebijakan hutang mmpunyai pengaruh kedisiplinan menejer karena hutang yang cukup besar akan menimbulkan kesulitan keuangan dan beresiko menjadi bangkrut.

Menurut Ilham Ismail (2015) "proxy dari kebijakan hutang pada penelitian ini adalah Debt to Equity ratio (DER). Tujuan nya untuk mengukur kemampuan perusahaan dalam membayar hutang-hutang yang dimilikinya dengan modal atau ekuitas yang ada". Debt Equity Ratio atau Rasio Hutang dapat dirumuskan sebagai berikut :

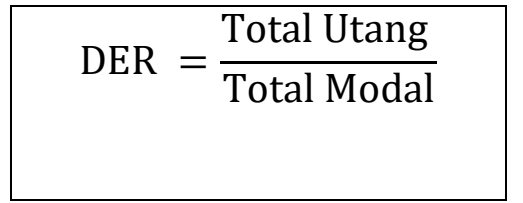

Ilham Ismail (2015)

Martono dan Harjito (2007) mengungkapkan bahwa "DER yaitu perbandingan total utang yang dimiliki perusahaan dengan modal sendiri (ekuitas)" kemampuan pemilik perusahaan dengan equity yang dimiliki untuk membayar hutang kepada kreditur maka rasio ini sangat berguna untuk mengetahui jumlah dana yang disediakan 
kreditor dengan pemilik perusahan yang berkaitan dengan kebijakan pendanaan maka dapat diukur menggunkan Debt to equity.

\section{Paradigma Penelitian}

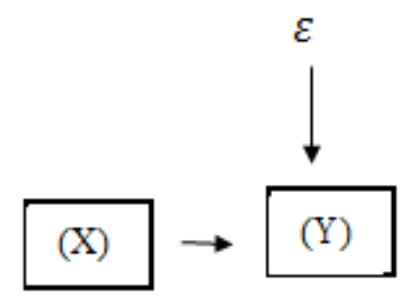

Gambar 1

Paradigma Penelitian

Keterangan :

X : Free Cash Flow

Y : Kebijakan Hutang

$\varepsilon \quad$ : variabel yang tidak diteliti dalam penelitian

\section{METODE PENELITIAN}

Penelitian ini dilakukan pada PT Indfood Sukses Makmur Tbk. Metode yang digunakan adalah metode penelitian deskriptif asosiatif untuk mengetahui hubungan antara dua variabel atau lebih. Hubungan antar variabel tersebut dirumuskan dalam hipotesis yang akan diuji. Serta menggunakan pendekatan kuantitatif.

Penelitian ini menggunakan data sekunder yang bersumber dari laporan keuangan triwulan dari tahun 2011 - 2018 PT Indfood Sukses Makmur Tbk yang terdaftar di Bursa Efek Indonesia melalui (www.idx.co.id) yang kemudian dipelajari, diolah dan dianalisis. Laporan keuangan digunakan untuk mengetahui kebijakan hutang. Setelah laporan keuangan dihitung lalu dilakukan analisis dan pengujian terhadap kebijakan hutang tersebut.

Analisis data dalam penelitian ini menggunakan analisis regresi linear sederhana termasuk uji koefisien determinasi, dengan bantuan program SPSS (Statistic Product \& Services Solution) versi 24. 


\section{HASIL PENELITIAN}

\section{Hasil Analisis Regresi Linear Sederhana}

Regresi linear sederhana didasarkan pada pola hubungan fungsional ataupun kausal satu variabel independen dengan satu variabel dependen (Sugiyono, 2013).

Tabel 1.

Hasil Uji Regresi Linear Sederhana

Coefficients $^{\mathrm{a}}$

\begin{tabular}{|c|c|c|c|c|c|c|c|c|}
\hline \multirow{2}{*}{\multicolumn{2}{|c|}{ Model }} & \multicolumn{3}{|c|}{ Unstandardized Coefficients } & \multicolumn{2}{|c|}{ Standardized Coefficients } & \multirow[b]{2}{*}{$\mathrm{T}$} & \multirow{2}{*}{ Sig. } \\
\hline & & B & & $\begin{array}{l}\text { Std. } \\
\text { Error }\end{array}$ & Beta & & & \\
\hline \multirow[b]{2}{*}{1} & (Constant) & & 0.693 & 1.301 & & & 0.53 & 0.598 \\
\hline & $\begin{array}{l}\text { CASH } \\
\text { FLOW }\end{array}$ & & -0.176 & 0.062 & & -0.46 & $\begin{array}{r}- \\
2.84\end{array}$ & 0.008 \\
\hline
\end{tabular}

a. Dependent Variable: DER

Sumber : Data Primer, 2019

Dari output regresi linear sederhana tersebut diperoleh persamaan sebagai berikut :

$$
\mathrm{Y}=-0,176(\mathrm{X}) 0,693
$$

\section{Koefisien Determinasi $\left(\mathbf{R}^{2}\right)$}

Tabel 2

Hasil Koefisien Determinasi

\begin{tabular}{ccccc}
\hline \multicolumn{4}{c}{ Model Summary } \\
\hline Model & $\mathrm{R}$ & R Square & $\begin{array}{c}\text { Adjusted } \mathrm{R} \\
\text { Square }\end{array}$ & $\begin{array}{c}\text { Std. Error of the } \\
\text { Estimate }\end{array}$ \\
\hline 1 & $.460^{\mathrm{a}}$ & 0.212 & 0.185 & 3.74593 \\
\hline
\end{tabular}

a. Predictors: (Constant), CASH FLOW

Sumber : Data Primer, 2019

$\mathrm{R}$ Square menjelaskan seberapa besar variasi $\mathrm{Y}$ yang disebabkan oleh $\mathrm{X}$, dari hasil pengolahan data diperoleh nilai R2 sebesar 0,212 atau $1 \%$, artinya $1 \%$ tingkat free cash flow dipengaruhi oleh variabel kebijakan hutang.

\section{Koefisien korelasi $(\mathbf{R})$}

Tabel 3

Hasil Koefisien Korelasi

\begin{tabular}{ccccc}
\hline \multicolumn{4}{c}{ Model Summary } \\
\hline Model & $\mathrm{R}$ & R Square & $\begin{array}{c}\text { Adjusted R } \\
\text { Square }\end{array}$ & $\begin{array}{c}\text { Std. Error of the } \\
\text { Estimate }\end{array}$ \\
\hline 1 & $.460^{\mathrm{a}}$ & 0.212 & 0.185 & 3.74593 \\
\hline Predictors: (Constant), CASH FLOW & &
\end{tabular}


Sumber : Data Primer (Kuesioner), 2019

Dari hasil olah data dengan menggunakan SPSS diperoleh hasil nilai koefisien korelasi sebesar 0,460 artinya hubungan antara variabel $\mathrm{X}$ yaitu Free Cash Flow dan variabel Y yaitu Kebijakan Hutang dalam kategori 0,40-0,599 yang menunjukkan bahwa tingkat hubungan yang sedang antara Free Cash Flow dan Kebijakan Hutang.

\section{Uji Signifikasi Secara Parsial (Uji t)}

Tabel 4

Hasil Uji t

\section{Coefficients $^{\mathrm{a}}$}

\begin{tabular}{|c|c|c|c|c|c|c|}
\hline \multirow{2}{*}{\multicolumn{2}{|c|}{ Model }} & \multicolumn{2}{|c|}{$\begin{array}{l}\text { Unstandardized } \\
\text { Coefficients }\end{array}$} & \multirow{2}{*}{$\begin{array}{c}\text { Standardized } \\
\text { Coefficients } \\
\text { Beta } \\
\end{array}$} & \multirow[t]{2}{*}{$\mathrm{t}$} & \multirow[t]{2}{*}{ Sig. } \\
\hline & & $\mathrm{B}$ & Std. Error & & & \\
\hline \multirow[b]{2}{*}{1} & (Constant) & 0.693 & 1.301 & & 0.53 & 0.598 \\
\hline & $\begin{array}{l}\text { CASH } \\
\text { FLOW }\end{array}$ & -0.176 & 0.062 & -0.46 & 2.84 & 0.008 \\
\hline
\end{tabular}

a. Dependent Variable: DER

Sumber : Data Primer, 2019

Hasil uji parsial untuk Free Cash Flow nilai sig. 0,015 < 0,05, sedangkan nilai $\mathrm{t}$ hitung sebesar $-2,838$ dan t tabel 2,041. Sesuai dengan kriteria pengujian bahwa jika $t$ hitung > t tabel $(2,838>2,041)$ artinya secara parsial Free Cash Flow berpengaruh signifikan terhadap Kebijakan Hutang.

\section{PEMBAHASAN}

\section{Hasil Uji Hipotesis}

Berdasarkan hasil perhitungan SPSS, nilai t hitung sebesar 2,838 dengan mengambil taraf signifikan $\alpha$ sebesar 5\% maka t tabel sebesar 2,042, sehingga t hitung $>$ t tabel $(2,838>2,041)$ dan hasil nilai sig. $0,015<0,05$ menunjukkan bahwa variabel Free Cash Flow (X) berpengaruh terhadap Kebijakan Hutang (Y).

Berdasarkan hasil analisis dan uji hipotesis didapatkan ada pengaruh yang signifikan variabel free cash flow terhadap kebijakan hutang perusahaan. Kebijakan hutang perusahaan merupakan bagian dari perimbangan jumlah hutang jangka pendek, hutang jangka panjang dan kebijakan yang diambil oleh pihak manajemen dalam rangka memperoleh sumber pembiayaan bagi perusahaan sehingga dapat digunakan untuk pembiayaan aktivitas operasional perusahaan. 
Laporan pembiayaan aktivitas operasional perusahaan sangat penting untuk menggunakan Laporan arus kas, merupakan laporan yang melaporkan keluar masuknya arus kas didalam perusahaan selama satu periode. Laporan arus kas sangat berguna bagi perusahaan karena memberikan informasi mengenai kemampuan suatu perusahaan dalam menghasilkan kas dari aktivitas operasi, melakukan investasi, melunasi kewajiban, dan membayar deviden. Dalam suatu perusahaan, free cash flow atau arus kas bebas berperan penting karena jika free cash flow nya besar maka berpengaruh terhadap perusahaan untuk menunjukan bahwa perusahaan mampu mengembalikan tingkat pengembalian modal (Dharmmesta, Basu Swastha dan Handoko, 2014).

\section{SIMPULAN}

Berdasarkan analisis yang dilakukan, menunjukkan hasil secara parsial Free Cash Flow berpengaruh yang signifikan terhadap Kebijakan Hutang yang artinya semakin tinggi nilai Free Cash Flow maka perusahaan akan semakin kuat dalam menanggung hutang tersebut.

\section{DAFTAR PUSTAKA}

Agus, H., \& Martono. (2007). Manajemen Keuangan, Yogyakarta, Ekonisia Buchory, H.A \& Saladin, D. (2010). Manajemen Pemasaran. Bandung : Linda karya Dharmmesta, B., S., \& Hani, H. (2014). Manajemen Pemasaran Analisis Perilaku Konsumen. Yogjakarta: BPFE Yogjakarta.

Ika S., Ferina, Rina T., Rina \& Ilham, I. (2015). Pengaruh Kebijakan Dividen, Kebijakan Hutang, dan Profitabilitas Terhadap Nilai Perusahaan. Jurnal Akuntanika 1 (2).

Sudarso, E. (2016). Kualitas Layanan, Nilai Fungsional, Nilai Emosional, dan Kepuasan Konsumen : Sebuah Studi Kasus. Jurnal Ekonomi Bisnis dan Kewirausahaan, 15 (3)

Sugiyono. (2013) Metodelogi Penelitian Kuantitatif, Kualitatif Dan R\&D. Bandung: Alfabeta

Surachman S. (2008). Dasar-Dasar Manajemen Merek. Malang: Bayumedia Publishing.

Surjaatmadja, S. (2008). Dasar-dasar Manajemen Merek. Edisi Pertama. Cetakan Pertama. Malang, Jawa Timur: Banyumedia Publishing-Malang.

WR Murhadi. (2013). Analisis Laporan Keuangan: Proyeksi dan Valuasi Saham. Jakarta: Salemba Empat 